\title{
The Ameliorative Effects of Ethyl Pyruvate and Dimethyl Sulfoxide on Ischemic Tissue Injury in Experimental Carbon Monoxide Intoxication
}

\author{
(1) Sinan Paslı', (1) Melih İmamoğlu², (1) Mustafa Çiçek ${ }^{3}$, (1) Metin Yadigaroğlu4, (1) Aynur Șahin ${ }^{5}$, (1) Yunus Karaca \\ (1) Esin Yuluğ $\breve{b}^{6}$, (1) Özgür Tatlı 5
}

${ }^{1}$ Clinic of Emergency Medicine, Gümüşhane State Hospital, Gümüşhane, Turkey

${ }^{2}$ Clinic of Emergency Medicine, Rize State Hospital, Rize, Turkey

${ }^{3}$ Clinic of Emergency Medicine, Bayburt State Hospital, Bayburt, Turkey

${ }^{4}$ Clinic of Emergency Medicine, Fatih State Hospital, Trabzon, Turkey

5Department of Emergency Medicine, Karadeniz Technical University Faculty of Medicine, Trabzon, Turkey

${ }^{6}$ Department of Histology and Embryology, Karadeniz Technical University Faculty of Medicine, Trabzon, Turkey

\begin{abstract}
Aim: The purpose of this study was to investigate the protective effects of ethyl pyruvate (EP) and dimethyl sulfoxide (DMSO) on ischemic tissue in brain and cardiac and hepatic tissues in experimentally induced carbon monoxide (CO) intoxication.

Material and Methods: Thirty-five mature female Sprague Dawley rats were randomized into five groups of seven animals each. Group 1 received no CO or treatment. Rats in groups 2, 3, 4 and 5 were made to inhale a high-concentration $5000 \mathrm{ppm}$ CO gas mixture for 60 min at $4 \mathrm{~L} / \mathrm{min}$. CO levels were then measured from $1 \mathrm{~mL}$ tail vein blood. Group 2 received no therapeutic agent, group 3 received $6 \mathrm{mg} / \mathrm{kg}$ intraperitoneal (ip) DMSO, group 4 received $50 \mathrm{mg} / \mathrm{kg}$ ip EP, group 5 received $50 \mathrm{mg} / \mathrm{kg}$ EP and $6 \mathrm{mg} / \mathrm{kg}$ DMSO ip. All rats were sacrificed by decapitation. Brain, cardiac and hepatic tissues were removed and histopathological scores were compared.

Results: Comparison of group 2 with group 3 and group 2 with group 5 revealed that DMSO alone and EP + DMSO exhibited a reducing effect on degree of cerebral neuronal alteration, degenerative neuron rates, and total cardiac injury score $(p=0.005, p=0.002, p=0.004$ and $p=0.002, p=0.001, p=0.004$ respectively). There was no histopathological difference between group 2 and group 4 suggesting EP alone had no therapeutic effect on histopathological injury.

Conclusion: Based on our study findings, EP administered alone exhibited no protective effects on the organ injuries investigated, while DMSO exhibited reducing effects on degree of neuron alteration, rates of degenerative neurons, and total cardiac injury scores. An ameliorating effect on cardiac and hepatic injury was more prominent with combined treatment.
\end{abstract}

Keywords: Carbon monoxide, dimethyl sulfoxide, ethyl pyruvate, experimental, intoxication

\section{Introduction}

Carbon monoxide (CO) is a colorless, odorless, tasteless, nonirritating gas which normally presents at a level of $0.001 \%$ in the atmosphere. It emerges when carbon-based compounds used as fuels for cooking and heating are incompletely consumed, or during fires (1). CO is one of the most important global agents in injury- and intoxication-related mortality (2). Children and the elderly are more rapidly affected. Other factors increasing disposition are exercise, stress, and anemia. High atmospheric concentrations and long-term exposure are other important factors. Due to their high oxygen requirements, brain, heart, and liver are the most susceptible organs to the hypoxic effects of CO exposure (3). Studies have determined that the cardiac effect is associated with 
formation of carboxyhemoglobin $(\mathrm{COHb})$ which causes hypoxia, and that CO-related oxidative stress leads to neurological injury (4). The synthesis of reactive oxygen products increases secondary to tissue hypoxia in $\mathrm{CO}$ intoxication. The numbers of studies of the place and importance of antioxidant therapies as an alternative to oxygen therapy are therefore increasing rapidly. Several studies agree that antioxidant therapy can be a novel therapeutic option in the treatment of CO intoxication (5). Dimethyl sulfoxide (DMSO) is a strong penetration enhancer, cell fusogen and cryoprotectant. It is a widely used molecule in cell biology (6). It is mainly intended for use in many gastrointestinal diseases, thanks to its anti-inflammatory and reactive oxygen species cleaning activities (7). DMSO crosses the blood-brain barrier and has been effective in treating traumatic brain edema $(8,9)$. It has also been used in the treatment of musculoskeletal disorders (10), rheumatologic diseases (11), dermatological diseases and as a topical analgesic (12). In addition, it has been recommended for the treatment of Alzheimer's disease (13). Ethyl pyruvate (EP) is a stable and simple lipophilic ester originating from the endogenous metabolite pyruvate. It has been shown to provide protection against inflammation and reduce organ dysfunction in some models of clinical disease, such as burns, sepsis, and acute pancreatitis $(14,15)$. Shen et al. (16) has shown that ethyl pyruvate improves hypoxic-ischemic brain injury through the anti-inflammatory and anti-cell death mechanism. The effect of ethyl pyruvate on ischemia reperfusion injury has also been demonstrated by scientists. Hu et al. (17) have shown that ethyl pyruvate reduces myocardial ischemia reperfusion injury by inhibiting HMGB1 protein expression in rats. In addition, Tsung et al. (18) has shown that ethyl pyruvate protects against hepatic ischemia / reperfusion (I/R) injury by reducing hepatic necrosis and apoptosis. The purpose of this study was to investigate the protective effects of ethyl pyruvate and DMSO at the histopathological level in experimentallyinduced CO intoxication in rats.

\section{Materials and Methods}

\section{Study Design}

This randomized, controlled, non-blinded, interventional animal study was performed following receipt of approval from Karadeniz Technical University Animal Care and Ethics Committee (approval no: 2016/23). A 5000 ppm experimental CO intoxication protocol was applied when establishing the experimental model (19). Intraperitoneal (ip) administration of $6 \mathrm{mg} / \mathrm{kg}$ DMSO and $50 \mathrm{mg} /$ $\mathrm{kg}$ EP was planned in the light of previous studies.

\section{Animal Subjects}

Thirty-five mature female Sprague Dawley rats (10-week old, weighing $250 \pm 25 \mathrm{~g}$ ) were used in this study. Until the day of the study, rats were housed in steel cages at $22^{\circ} \mathrm{C} \mathrm{room} \mathrm{temperature}$ with access to water and standard rat chow. The $\mathrm{CO}$ gas to be used in the experimental protocol was ordered from HABAS Sınai ve Tarım Gazlar Endüstrisi A.Ş. (Izmit, Turkey) such as to contain 5000 pp CO concentrations. A special mechanism consisting of a two-chamber aquarium tank $100 \times 40 \times 50 \mathrm{~cm}$ in size, with holes capable of receiving gas from one end and permitting gas to escape from the other was employed for the experiment.

\section{Study Protocol}

The 35 rats were randomly assigned into five groups of seven animals each.

Group 1 (Sham group, $\mathrm{n}=7$ ): After being placed into the glass container, these rats inhaled room air for $60 \mathrm{~min}$, after which CO levels were measured from $1 \mathrm{~mL}$ blood gas from the tail veins.

Group 2 (Control group, $\mathrm{n}=7$ ): After being placed into the glass container, these rats inhaled high-concentration 5000 ppm CO gas mixture at $4 \mathrm{~L} / \mathrm{min}$ for $60 \mathrm{~min}$, after which CO levels were measured in $1 \mathrm{~mL}$ blood gas from the tail veins.

Group 3 (DMSO group, $\mathrm{n}=7$ ): After being placed into the experimental glass container, these rats inhaled highconcentration 5000 ppm CO gas mixture at $4 \mathrm{~L} / \mathrm{min}$ for $60 \mathrm{~min}$, after which CO levels were measured in $1 \mathrm{~mL}$ blood gas from the tail veins. Immediately after removal from the glass jar, $6 \mathrm{mg} / \mathrm{kg}$ DMSO was administered ip.

Group 4 (EP group, $n=7$ ): After being placed into the experimental glass container, these rats inhaled high-concentration $5000 \mathrm{ppm}$ $\mathrm{CO}$ gas mixture at $4 \mathrm{~L} / \mathrm{min}$ for $60 \mathrm{~min}$, after which CO levels were measured in $1 \mathrm{~mL}$ blood gas from the tail veins. Immediately after removal from the glass jar, $50 \mathrm{mg} / \mathrm{kg}$ EP was administered ip.

Group 5 (DMSO plus EP group, $n=7$ ): After being placed into the experimental glass container, these rats inhaled highconcentration 5000 ppm CO gas mixture at $4 \mathrm{~L} / \mathrm{min}$ for $60 \mathrm{~min}$, after which CO levels were measured in $1 \mathrm{~mL}$ blood gas from the tail veins. Immediately after removal from the glass jar, $50 \mathrm{mg} / \mathrm{kg}$ $\mathrm{EP}$ and $6 \mathrm{mg} / \mathrm{kg}$ DMSO were administered ip.

\section{Histopathological Examination}

All rats were sacrificed by decapitation $24 \mathrm{~h}$ after removal from the glass tank. Brain, cardiac, and hepatic tissues were removed. Each tissue was divided into two parts down the midline, ensuring that each part contained all layers. These tissue specimens were fixed in 10\% neutral formalin for $48 \mathrm{~h}$. Specimens were dehydrated by being passed through increasingly greater alcohol concentrations, made transparent in xylene, and embedded in paraffin blocks for histopathological examination. Sections $5 \mu \mathrm{m}$ in thickness were taken from the paraffin block using a 
fully automatic microtome (Leica RM 2255, Tokyo, Japan) and stained with hematoxylin-eosin (H\&E) for detailed evaluation. Cerebral tissue specimens were also stained with cresyl violet for more detailed examination. Preparates were evaluated by an experienced histologist (E.Y.) blinded to the study groups using a light microscope (Olympus BX-51; Olympus Optical Co., Tokyo, Japan). Preparates were scored semi-quantitatively for all organs ( $0=$ none, $1=$ mild, $2=$ moderate, $3=$ severe). Tissues' histopathological damage scores are shown in Table 1 $(20,21,22,23)$. Neuronal alterations in cerebral tissue were scored histologically (20).

Total cardiac and hepatic injury scores were obtained by adding the histopathological parameter scores for cardiac and hepatic tissues, and statistical comparisons were performed on the basis of these scores.

\section{$\mathrm{COHb}$ Measurement}

$\mathrm{COHb}$ levels were determined using an automatic blood gas measurement device (Rapidlab 1265, Bayer Health Care LLC, Pittsburgh, PA, USA).

\section{Statistical Analysis}

Statistical analyses were performed on SPSS 23.0 (IBM SPSS, Armonk, NY, USA) software. Results were expressed as median and $25-75 \%$ quartiles. Kruskal-Wallis analysis of variance was used for group comparisons (Mann-Whitney $U$ test with post hoc Bonferroni correction). $P$ values $<0.05$ were considered statistically significant.

\section{Table 1. Histopathological classification of tissue damage in brain, cardiac, and hepatic tissues}

Brain

Neuronal changes (20)

1- Group with mildly shrunken neurons with / without cytoplasmic vacuolization,

2-Moderately shrunken neurons (eosinophilic cytoplasm) and increased nuclear basophilia or vacuoles with cytoplasm and vesicular nucleus,

3-Severely shrunken neurons (eosinophilic cytoplasm), piknotic nucleus

Cells with shrinkage in the cell body, loss of Nissl substance and eosinophilia, and cells with a shrunken nucleus were regarded as degenerative (21)

Cardiac (22)

Myocardial cell degeneration

0 -No degeneration in myocytes,

1-Some degenerated myocytes,

2-Approximately 50\% myocyte degeneration,

3-More than 50\% myocyte degeneration

(Myocytes with multifocal vacular degeneration and piknotic nuclei were regarded as degenerative.)

Edema, vascular congestion, increased spaces between muscle fibers

0-None

1-Mild

2-Moderate

3-Severe

Hepatic

Hepatic injury (23)

0-None or minimal

1-Mild injury wth cytoplasmc vacuolization and focal nuclear piknosis,

2-Diffuse nuclear piknosis of variable severity, and loss of cell margins,

3-Severe necrosis with neutrophil infiltration and hemorrhage

Hepatocyte degeneration, vascular congestion, and sinusoidal dilatation (23)

0-None

1-Mild

2-Moderate

3-Severe 


\section{Results}

Mean $\mathrm{COHb}$ concentrations for all groups are shown in Table 2. Although all groups were exposed to CO for the same time and at the same concentrations, CO levels differed significantly among the groups. Analysis revealed no significant differences between group 2, 3, and 4 CO levels among the CO-exposed groups. However, differences were determined between group 5 co levels and those of groups 2 and $4(p=0.033$ and 0.019, respectively).

\section{Histopathological Evaluation}

The study groups' histopathological results and median injury values are shown in Table 2. Kruskal-Wallis analysis performed to

\begin{tabular}{|l|l|l|l|l|l|}
\hline \multicolumn{6}{|l|}{ Table 2. Mean carbon monoxide levels among the groups } \\
\hline COHb & Group 1 & Group 2 & Group 3 & Group 4 & Group 5 \\
\hline Median & 0.350 & 36.4 & 29.05 & 35.850 & 18.600 \\
\hline Minimum & 0.3 & 25.2 & 22.7 & 24 & 11 \\
\hline Maximum & 4.4 & 47.8 & 39.9 & 52.6 & 33.8 \\
\hline 25-75\% & $0.3-3.4$ & $29.9-42.8$ & $23.3-38.1$ & $28.9-51.9$ & $14.6-28.3$ \\
\hline CO: Carbon monoxide, COHb: Carboxyhemoglobin \\
\hline
\end{tabular}

compare the five groups revealed significant differences between them in terms of injury parameters $(p=0.000)$. Bonferroni correction was applied to determine which groups representing the source of the variation (Table 3).

Brain tissue evaluation investigated shrinkage in the cell body, loss of Nissl substance and eosinophilia in cytoplasm, and degenerative neurons with a dark, shrunken nucleus. Diffuse pyramidal neurons with a normal architecture were observed in the cerebral cortex in group 1 (Figure 1). Diffuse degenerative neurons were observed in all layers of the cortex in group 2 (Figure 2). Diffuse pyramidal neurons with normal architecture were observed in addition to degenerative neurons in group 3 (Figure 3). Occasional pyramidal neurons with normal architecture in addition to diffuse degenerative neurons in all layers were observed in group 4 (Figure 4). Diffuse pyramidal neurons with normal morphology in addition to degenerative neurons were observed in group 5 (Figure 5). Cardiac tissue evaluation revealed a normal myocardial cell structure in group 1 (Figure 6). Degeneration in cardiac muscle cells and vascular congestion and edema between muscle fibers were observed in group 2 (Figure 7). Cardiac muscle cells in group 3 exhibited a close to normal morphology, and occasional vascular

\begin{tabular}{|c|c|c|c|c|c|c|}
\hline $\begin{array}{l}\text { Histopathological } \\
\text { Parameter }\end{array}$ & $\begin{array}{l}\text { Group } 1 \\
\text { (Sham) } \\
\text { Median \%95 Cl }\end{array}$ & $\begin{array}{l}\text { Group } 2(\mathrm{CO}) \\
\text { Median } 95 \% \mathrm{Cl}\end{array}$ & $\begin{array}{l}\text { Group } 3 \text { (DMSO) } \\
\text { Median } \% 95 \mathrm{Cl}\end{array}$ & $\begin{array}{l}\text { Group } 4 \text { (EP) } \\
\text { Median } 95 \% \mathrm{CI}\end{array}$ & $\begin{array}{l}\text { Group } 5(\mathrm{EP}+\mathrm{DMSO}) \\
\text { Median } 95 \% \mathrm{Cl}\end{array}$ & p values \\
\hline $\begin{array}{l}\text { Neuron } \\
\text { alterations (Grade) }\end{array}$ & $\begin{array}{l}1.500 \\
0.581-2.419\end{array}$ & $\begin{array}{l}3.000 \\
2.263-3.166\end{array}$ & $\begin{array}{l}1.000 \\
0.454-2.046\end{array}$ & $\begin{array}{l}3.000 \\
2.125-3.209\end{array}$ & $\begin{array}{l}2.000 \\
1.125-2.209\end{array}$ & $\begin{array}{l}0.005 \\
P^{1-2}=0.002 \\
P^{1-4}=0.004 \\
P^{2-3}=0.005\end{array}$ \\
\hline $\begin{array}{l}\text { Degenerative } \\
\text { brain cell rates }\end{array}$ & $\begin{array}{l}11.500 \\
6.834-17.666\end{array}$ & $\begin{array}{l}65.000 \\
59.246-70.468\end{array}$ & $\begin{array}{l}25.500 \\
18.069-30.931\end{array}$ & $\begin{array}{l}55.000 \\
50.519-61.815\end{array}$ & $\begin{array}{l}27.500 \\
22.074-31.593\end{array}$ & $\begin{array}{l}0.005 \\
p^{1-2.3 .4 .5}=0.002 \\
p^{2-3.5}=0.002 \\
p^{3-4}=0.002 \\
p^{4-5}=0.002\end{array}$ \\
\hline $\begin{array}{l}\text { Total cardiac } \\
\text { injury score }\end{array}$ & $\begin{array}{l}2.000 \\
0.163-3.837\end{array}$ & $\begin{array}{l}6.000 \\
5.077-6.066\end{array}$ & $\begin{array}{l}4.000 \\
3.454-5.046\end{array}$ & $\begin{array}{l}5.000 \\
4.249-6.417\end{array}$ & $\begin{array}{l}2.500 \\
1.399-3.601\end{array}$ & $\begin{array}{l}0.005 \\
P^{1-2.3 .4}=0.001 \\
P^{2-3}=0.004 \\
P^{2-5}=0.001 \\
P^{4-5}=0.002\end{array}$ \\
\hline $\begin{array}{l}\text { Total hepatic } \\
\text { injury score }\end{array}$ & $\begin{array}{l}2.000 \\
0.701-3.299\end{array}$ & $\begin{array}{l}7.000 \\
5.503-8211\end{array}$ & $\begin{array}{l}5.000 \\
3.909-7.091\end{array}$ & $\begin{array}{l}5.500 \\
4.802-6.865\end{array}$ & $\begin{array}{l}3.500 \\
2.810-4.524\end{array}$ & $\begin{array}{l}0.005 \\
P^{1-2.3 .4}=0.001 \\
P^{1-5}=0.003 \\
P^{2-5}=0.004 \\
P^{4-5}=0.002\end{array}$ \\
\hline \multicolumn{7}{|c|}{$\begin{array}{l}\text { CO: Carbon monoxide, EP: Ethyl pyruvate, DMSO: Dimethyl sulfoxide, Cl: Confidence interval, DMSO: Dimethyl sulfoxide } \\
\text { DMSO exhibited a greater capacity to reduce neuronal alteration grades, the degenerative neuron rates, and cardiac total injury score in Group 3, compared to Group } 2 \text { (CO) } \\
\text { ( } p=0.005, p=0.002 \text {, and } p=0.004 \text {, respectively). Comparison between Group } 5 \text { (EP }+ \text { DMSO) and Group } 2 \text { revealed that EP }+ \text { DMSO reduced the degenerative neuron rate, total } \\
\text { cardiac injury score, and total hepatic injury score ( } p=0.002, p=0.001 \text {, and } p=0.004 \text {, respectively). No significant difference was determined between Group } 3 \text { and Group } 5 \text { in } \\
\text { terms of treatment results }\end{array}$} \\
\hline
\end{tabular}




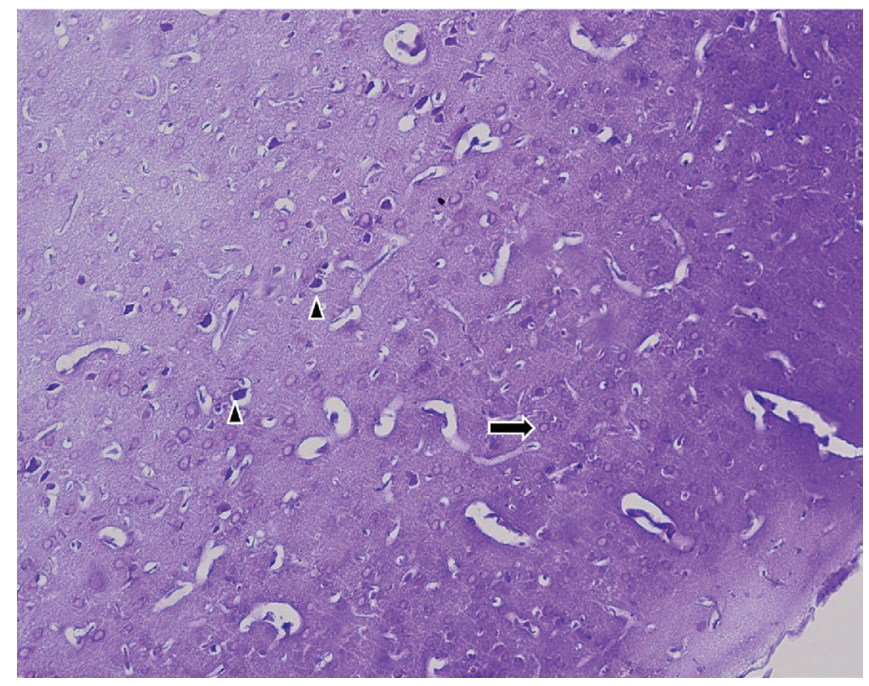

Figure 1. (Group 1) Cerebral cortex microphotographs (cresyl violet $X$ 200). Normal pyramidal neurons $(\uparrow)$, degenerative pyramidal neurons $(\Delta)$

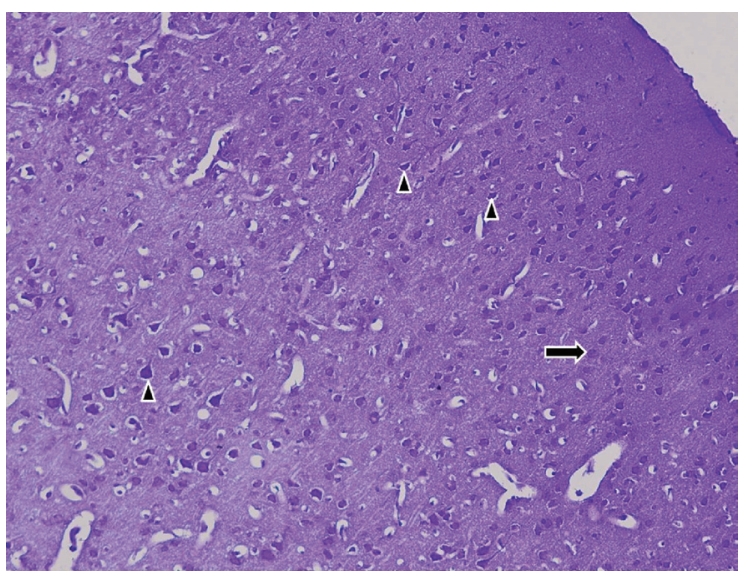

Figure 2. (Group 2) Cerebral cortex microphotographs (cresyl violet $X$ 200). Normal pyramidal neurons $(\uparrow)$, degenerative pyramidal neurons $(\Delta)$

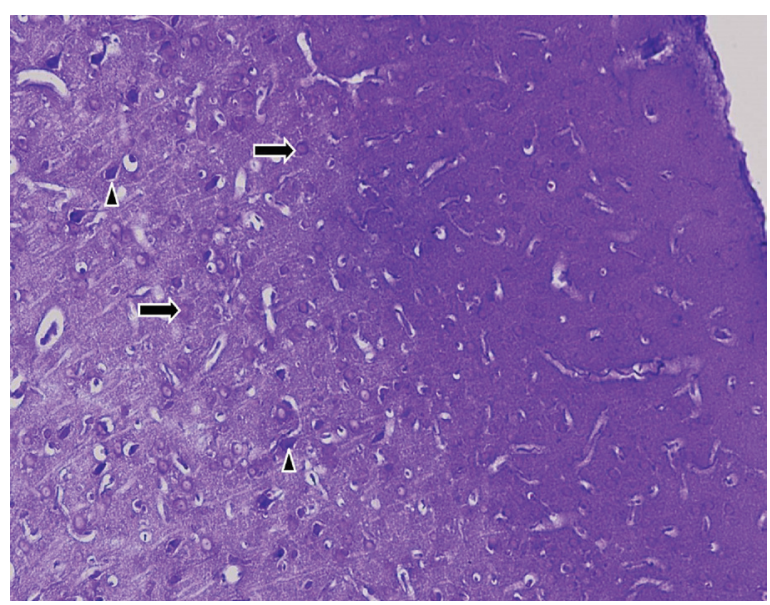

Figure 3. (Group 3) Cerebral cortex microphotographs (cresyl violet $X$ 200). Normal pyramidal neurons $(\uparrow)$, degenerative pyramidal neurons $(\Delta)$

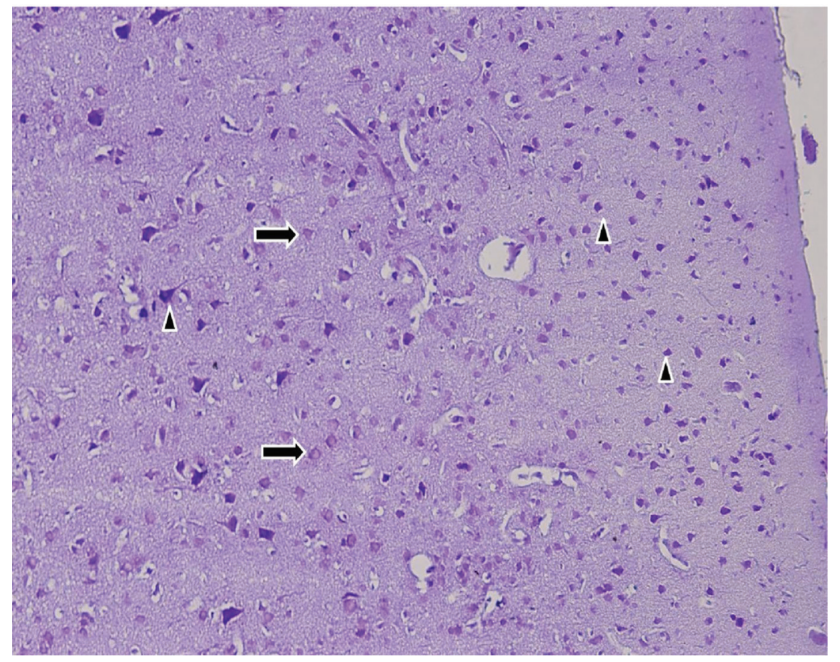

Figure 4. (Group-4) Cerebral cortex microphotographs (cresyl violet $X$ 200). Normal pyramidal neurons $(\uparrow)$, degenerative pyramidal neurons $(\Delta)$

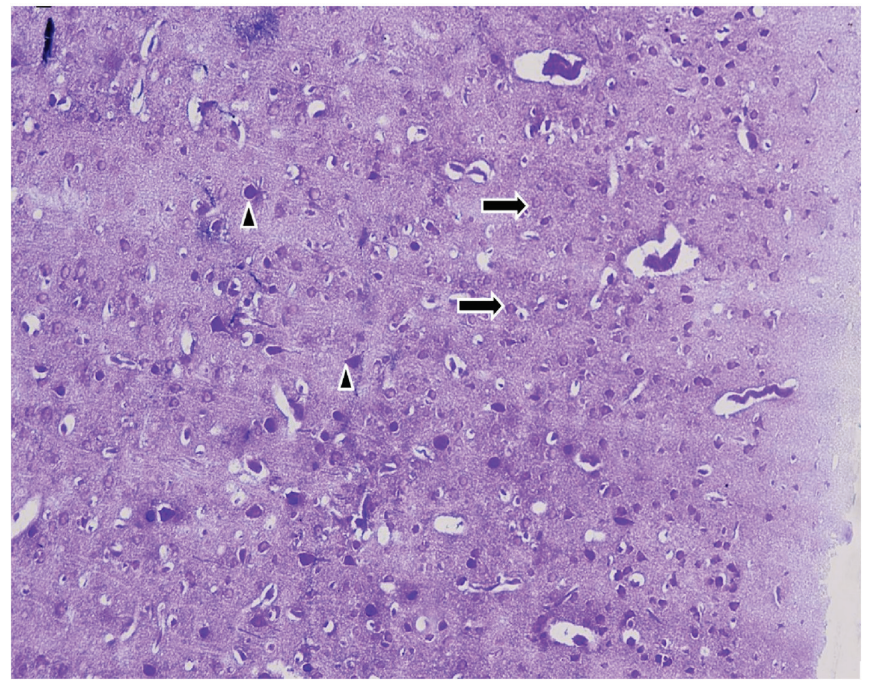

Figure 5. (Group-5) Cerebral cortex microphotographs (cresyl violet $X$ 200). Normal pyramidal neurons $(\uparrow)$, degenerative pyramidal neurons $(\Delta)$

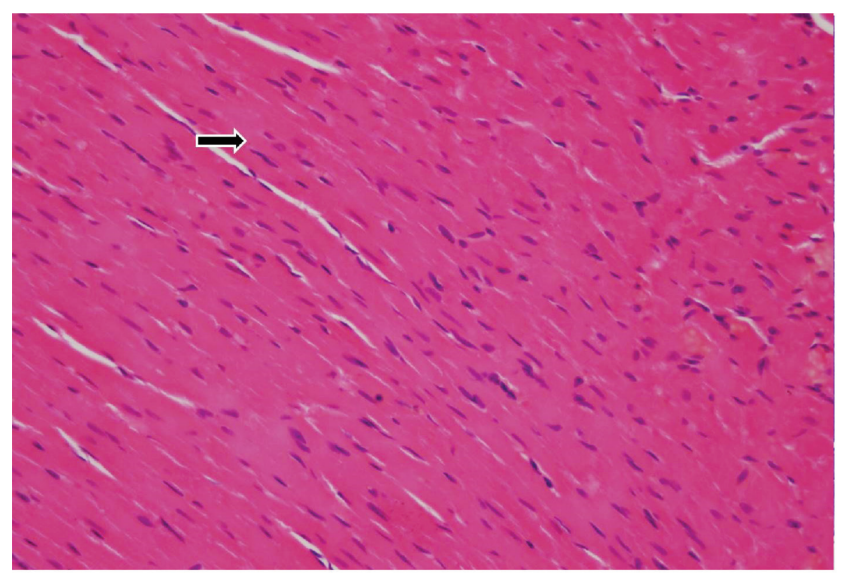

Figure 6. (Group-1) Myocardial tissue microphotograhs (H\&E X 200). Myocardial cells $(\uparrow)$ 
congestion and edema between muscle fibers were observed (Figure 8). Occasional degeneration in muscle fibers, and diffuse vascular congestion and edema were observed in group 4

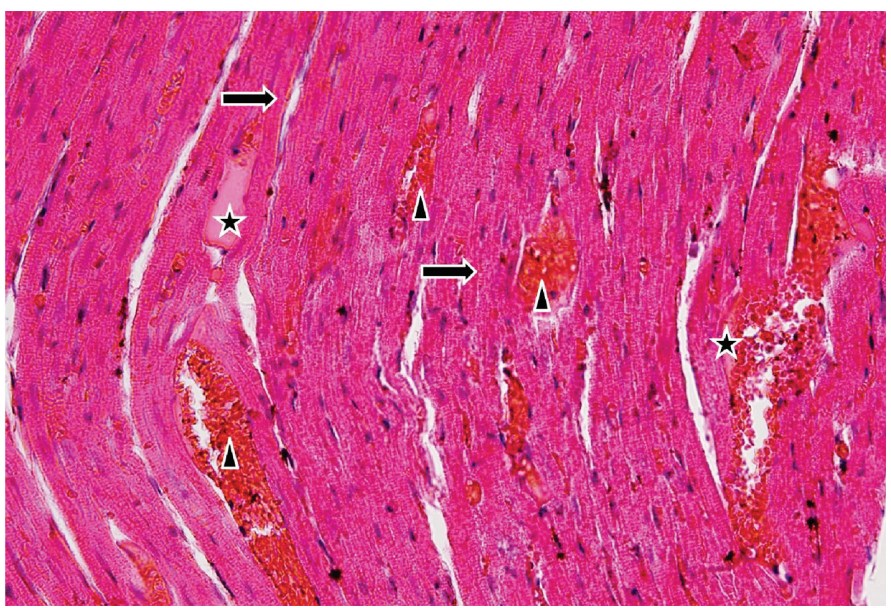

Figure 7. (Group-2) Myocardial tissue microphotograhs (H\&E X 200). Myocardial cells $(\uparrow)$, vascular congestion $(\Delta)$, edema (star)

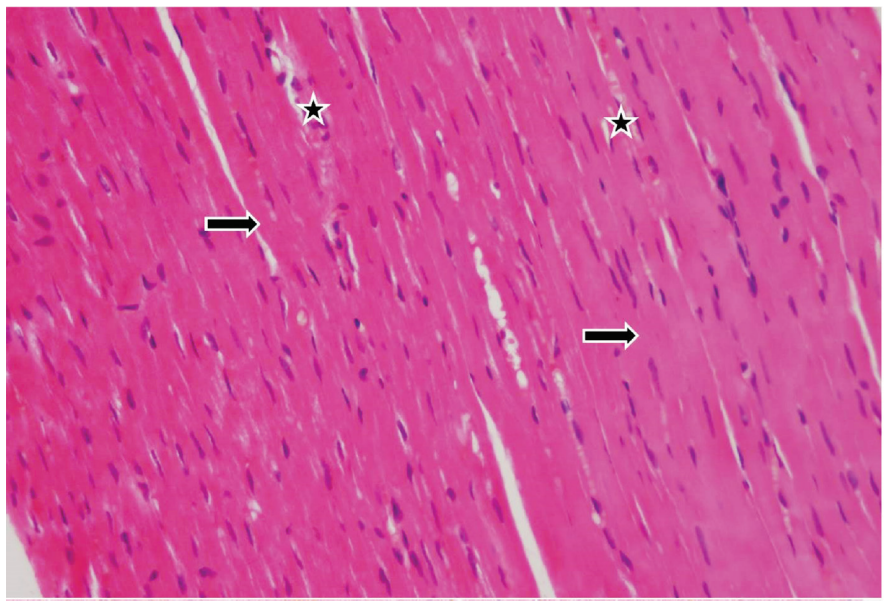

Figure 8. (Group-3) Myocardial tissue microphotograhs (H\&E X 200). Myocardial cells ( $\uparrow)$, edema (star)

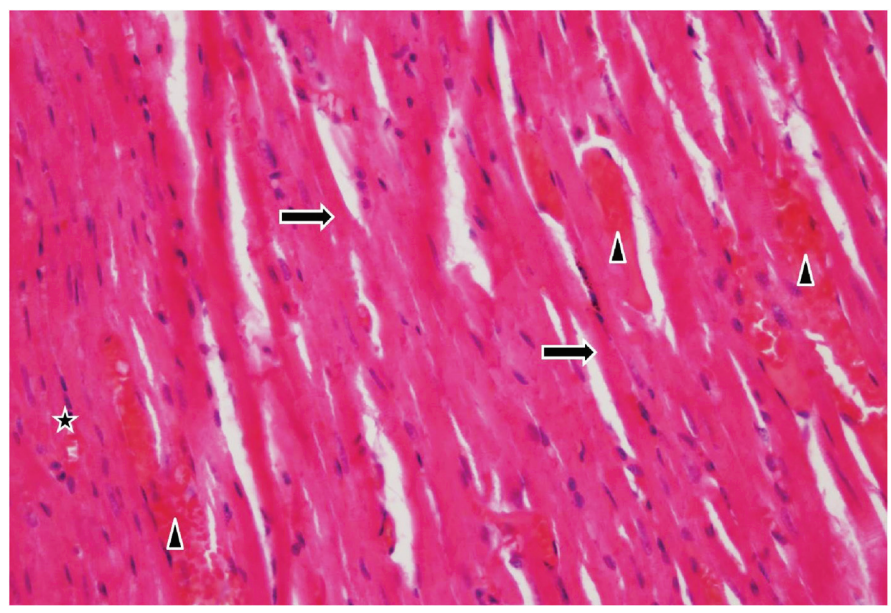

Figure 9. (Group-4) Myocardial tissue microphotograhs (H\&E X 200). Myocardial cells $(\uparrow)$, vascular congestion $(\Delta)$, edema (star)
(Figure 9). Cardiac muscle cells in group 5 exhibited a close to normal morphology, although occasional edema was observed between muscle fibers (Figure 10). Evaluation of hepatic tissues revealed a normal architecture in group 1. Normal morphology

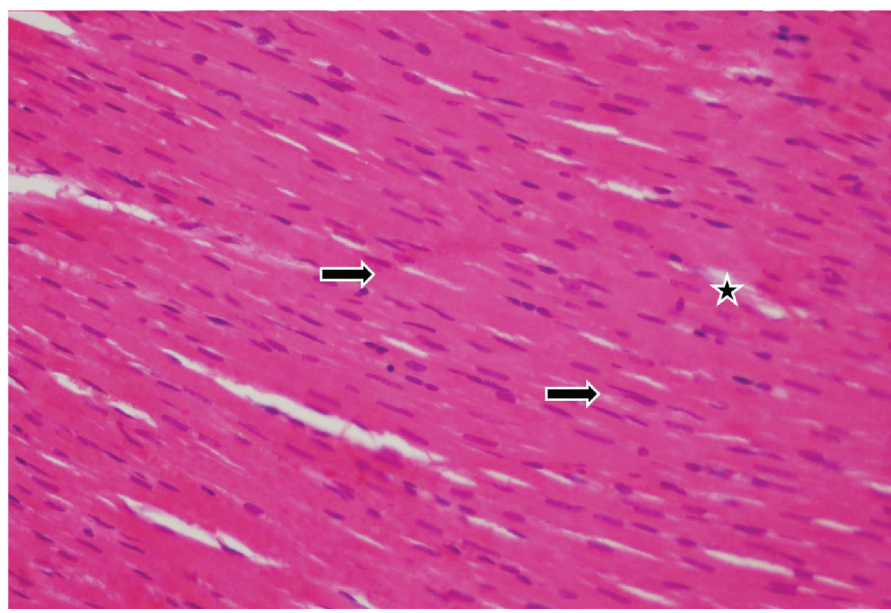

Figure 10. (Group-5) Myocardial tissue microphotograhs (H\&E X 200). Myocardial cells $(\uparrow)$, edema (star)

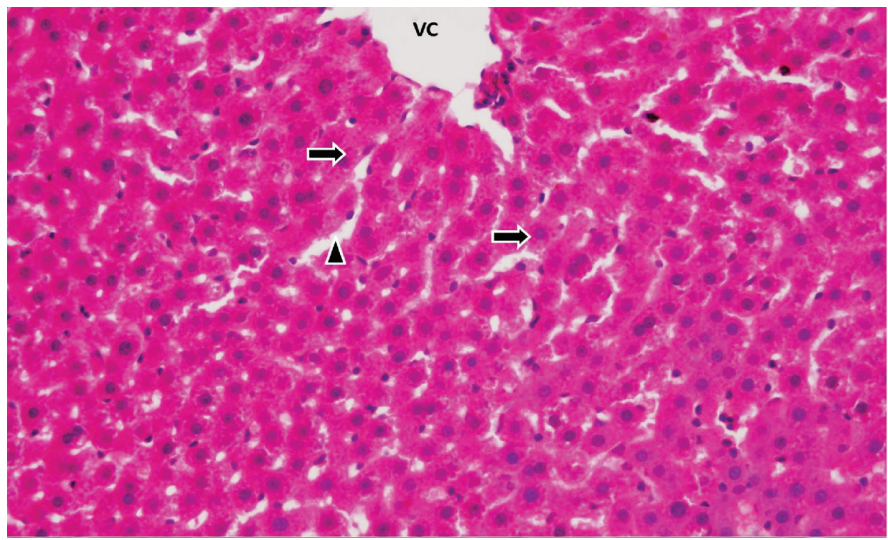

Figure 11. (Group-1) Liver tissue microphotograhs (H\&E X 200). Hepatocytes $(\uparrow)$, sinusoidal dilatation $(\Delta)$

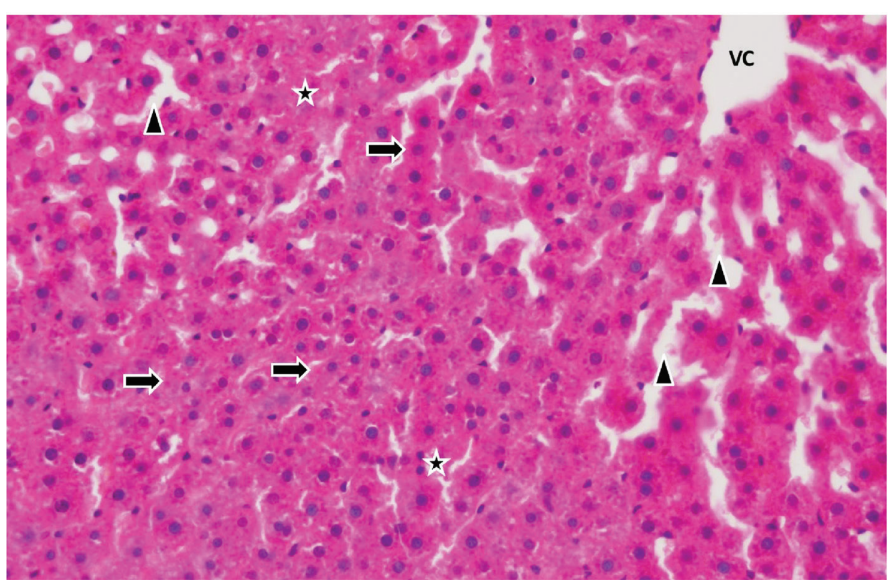

Figure 12. (Group-2) Liver tissue microphotograhs (H\&E X 200). Hepatocytes $(\uparrow)$, sinusoidal dilatation $(\Delta)$, hepatocytes with pyknotic nuclei (star) 
was observed in hepatocytes and sinusoidal spaces (Figure 11). Diffuse hepatocytes with pyknotic nuclei and cell margin losses were observed in group 2. Diffuse expansion of sinusoidal spaces were also determined (Figure 12). Occasional hepatocytes with pyknotic nuclei and cell margin losses were observed in group 3. Occasional sinusoidal dilatation was observed in areas close to the vena centralis (Figure 13). Diffuse sinusoidal dilatation and degenerative hepatocytes with pyknotic nuclei were observed in group 4 (Figure 14). In group 5, diffuse hepatocytes with normal morphology were observed in addition to occasional hepatocytes with pyknotic nuclei (Figure 15).

\section{Discussion}

This study investigated the protective effects of EP and DMSO against injury caused in important target organs including liver, brain and heart by potentially life-threatening CO intoxication, which is frequently encountered worldwide. Our findings indicated that EP had no protective effect against histopathological damage occurring in brain, cardiac, and hepatic tissues. However, our findings also suggested that DMSO might exhibit protective effects against damage occurring in brain and cardiac tissue, but not against hepatic injury. However, this needs to be confirmed by further studies.

CO intoxication is a frequent health problem in worldwide. Approximately 40.000 people present to emergency departments in the USA every year due to CO intoxication, and 5000-6000 individuals die due to exposure to the gas. $\mathrm{CO}$ is held responsible for more than half of all fatal intoxications worldwide (24). The most common sources of $\mathrm{CO}$ are engine exhaust gases, gaspowered engines, smoke caused by fires, and paints containing methylene chloride (1).

The pathophysiology of $\mathrm{CO}$ intoxication is complex. In addition to the cellular damage caused by $\mathrm{CO}$ itself, the hypoxia and ischemia produced by the CO-hemoglobin complex also play an important role in the process (25). Endogenously produced CO results in 1\% $\mathrm{COHb}$. Low endogenous $\mathrm{CO}$ levels are physiological, but excessive exogenous $\mathrm{CO}$ intake causes the principal problem (26). The main target of $\mathrm{CO}$ is hemoglobin $(\mathrm{Hb})$. The affinity of $\mathrm{Hb}$ for $\mathrm{CO}$ is 210 times greater than that for oxygen. $\mathrm{CO}$ binding to Hemoglobin $(\mathrm{Hb})$ replaces the oxygen in $\mathrm{Hb}$, giving rise to $\mathrm{COHb}$. Since the oxygen binding regions on the $\mathrm{COHb}$ molecule have a high affinity for oxygen, the oxygen binded to these is not presented to tissues. This increased affinity is known as the Haldane effect. As a result of the Haldane effect, a left shift occurs on the oxyhemoglobin curve, and it becomes difficult for oxygen to separate from $\mathrm{Hb}$ at the tissue level (27). Tissue hypoxia develops since oxygen cannot be transported to tissues. Following recent studies, it is now thought that different mechanisms are also involved in CO toxicity. One such is the damage occurring in the central nervous system with reoxygenation following hypoxia caused by $\mathrm{CO}$. Measuring $\mathrm{COHb}$ levels is today considered an important

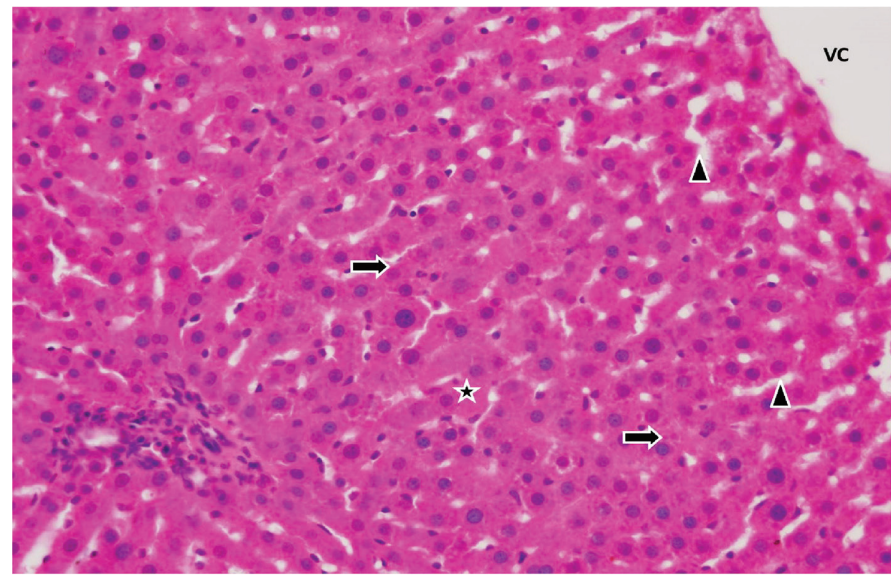

Figure 13. (Group-3) Liver tissue microphotograhs (H\&E X 200). Hepatocytes ( $\uparrow)$, sinusoidal dilatation $(\Delta)$, hepatocytes with pyknotic nuclei (star)

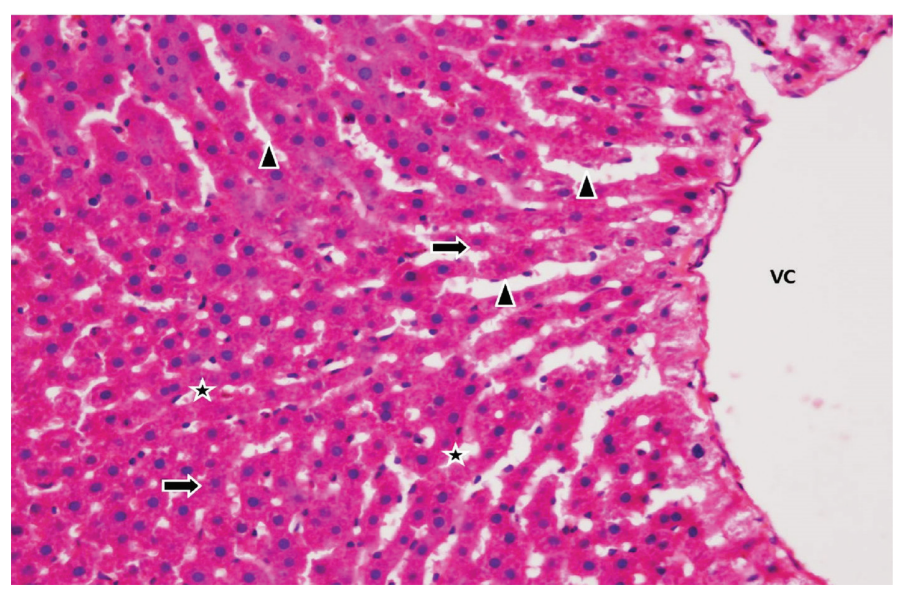

Figure 14. (Group-4) Liver tissue microphotograhs (H\&E X 200). Hepatocytes $(\uparrow)$, sinusoidal dilatation $(\Delta)$, hepatocytes with pyknotic nuclei (star)

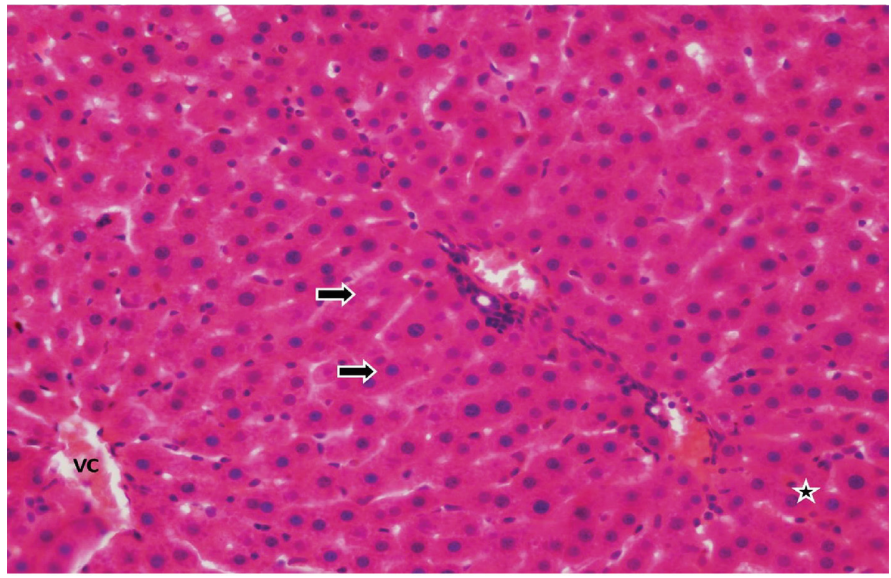

Figure 15. (Group-5) Liver tissue microphotograhs (H\&E X 200). Hepatocytes ( $\uparrow)$, hepatocytes with pyknotic nuclei (star) 
diagnostic technique. However, there is only a weak correlation between blood or tissue $\mathrm{COHb}$ levels and organ damage. Generally, $\mathrm{COHb}$ levels exceeding $60 \%$ result in mortality, while lower levels can result in clinical findings ranging from mild symptoms to coma, and it is not always possible to determine this by means of $\mathrm{COHb}$ levels (28). The therapeutic options in treatment planning for patients with $\mathrm{CO}$ intoxication are not numerous. Reactive oxygen product synthesis increases in $\mathrm{CO}$ intoxication secondary to tissue hypoxia. There is therefore a growing number of studies investigating the role and importance of antioxidant therapies as an alternative to oxygen therapy. In their experimental study, Wang et al. (29) showed that hydrogenrich saline solution reduced lipid peroxidation in cerebral tissue, and might therefore have a positive effect on neurological sequelae. Another study determined that $\mathrm{N}$-acetylcysteine (NAC) and melatonin reduced CO-induced brain and lung damage (30).

DMSO is an anti-inflammatory drug with a free oxygen radical (FOR) binding capacity (31). In clinical terms, it is used in the symptomatic treatment of interstitial cystitis (32). In experimental sepsis models, the inhibitory effects of DMSO on nuclear factor kappa receptors have been shown to regulate cellular gene expression in inflammation. It has been shown to exhibit a protective effect at the histological level with its powerful antioxidant activity in corrosive burns in experimental rat models $(33,34)$.

EP is a promising antioxidant and anti-inflammatory agent with known neuroprotective efficacy. Pyruvate, the end product of glycolysis and an initial substrate of the tricarboxylic acid cycle, is the anionic form of 2-oxo-proprionic acid. It has been reported to be capable of scavenging FORs and hydroxyl radicals. EP is the ethyl ester of pyruvate and has been reported to be a more powerful antioxidant than pyruvate (35).

To our knowledge, this is the first study investigating the protective effects of DMSO and EP on CO intoxication. DMSO is generally used in in vivo experiments as a solvent to dissolve chemicals. Because of this feature, it was used in the control group of many studies. In an experimental traumatic brain injury study, Di Giorgio et al. (36) wanted to evaluate the neuroprotective effect of curcumin and compare its effect with a known antioxidant $\alpha$-tocopherol. DMSO was used as a solvent for curcumin in the treatment groups in this study. In the study there was both DMSO group and normal saline group for control. Surprisingly, Di Giorgio et al. (36) found that $\alpha$-tocopherol, DMSO and all curcumin groups reduced the number of degenerating neurons compared to normal saline group and there was no significant difference between $\alpha$-tocopherol, DMSO and curcumin groups. They concluded that, DMSO was an effective neuroprotective agent in experimental traumatic brain injury (36). Similarly, in our study, we determined that DMSO had a therapeutic effect on ischemic injury.

There are several studies showing antioxidant and antiinflammatory effects of EP. Suha et al. (37) investigated the protective effects of NAC and EP in an experimental electric burn model and found that EP had protective effects on heart and brain (37). But in our study, we observed EP alone did not have a therapeutic effect on $\mathrm{CO}$ intoxication. This may be due to the dose of EP administered. Administration of EP at different doses may have a protective effect. Further studies are needed to demonstrate this.

Our findings revealed a significant difference in all parameters between group 1 (SHAM) and group 4 (EP) $(p=0.004)$, while no statistically significant difference was observed between group 2 (CO) and group 4. This suggested that EP alone had no therapeutic effect against histopathological injury. DMSO exhibited a greater capacity to reduce neuronal alteration grades, the degenerative neuron rates, and cardiac total injury score in group 3 , the DMSO group, compared to group 2 ( $p=0.005, p=0.002$, and $p=0.004$, respectively). Comparison between group 5 and group 2 revealed that $E P+D M S O$ reduced the degenerative neuron rate, total cardiac injury score, and total hepatic injury score $(p=0.002$, $p=0.001$, and $p=0.004$, respectively). However, this treatment had no ameliorating effect on neuronal alteration grade. No significant difference was determined between group 3 and group 5 in terms of treatment results. In other words, DMSO administered alone was as effective as DMSO + EP. Comparison between group 1 and group 5 revealed no difference in terms of injury occurring in cardiac tissue, suggesting that the protective effect of EP + DMSO was more prominent against damage occurring in the heart.

\section{Study Limitations}

Due to ethical committee requirements, this study was performed with a limited number of rats. It therefore needs to be supported by further studies involving larger sample numbers. Although this was a controlled study, it may not have mimicked typical cases of CO intoxication seen in clinical practice. In addition, this study examined only histopathological damage resulting from high-dose CO exposure over $60 \mathrm{~min}$ and the therapeutic effect of antioxidants against that injury. Higher-dose intoxication concentrations were not investigated. The therapeutic agents EP and DMSO were administered at doses of $50 \mathrm{mg} / \mathrm{kg}$, and $6 \mathrm{mg} /$ $\mathrm{kg}$, respectively, and the effectiveness of other doses could not be measured. In addition, although all animals inhaled CO in the same apparatus and for the same time, the same blood $\mathrm{COHb}$ level may not have been obtained in all rats. 


\section{Conclusion}

Our findings showed that EP alone exhibited no protective effect on the organ injuries investigated, while DMSO exhibited a reducing effect on neuronal alteration grade, degenerative neuron rates, and total cardiac damage score. The ameliorating effect of combined treatment was more prominent in cardiac and hepatic injury.

\section{Ethics}

Ethics Committee Approval: Karadeniz Technical University Animal Care and Ethics Committee (approval no: 2016/23).

Informed Consent: Informed consent was not obtained due to the fact that the study is animal testing.

Peer-review: Externally peer-reviewed.

\section{Authorship Contributions}

Surgical and Medical Practices: S.P., M.I.., Ö.T., Concept: S.P., M.İ., Ö.T., Design: S.P., M.İ., Ö.T., Data Collection or Processing: M.Ç., M.Y., Analysis or Interpretation: M.Ç., M.Y., E.Y., Literature Search: S.P., M.I., A.Ş., Y.K., Writing: S.P., M.İ., Ö.T.

Conflict of Interest: No conflict of interest was declared by the authors.

Financial Disclosure: The authors declared that this study received no financial support.

\section{References}

1. Kandiş H, Katırcı $\mathrm{Y}$, Karapolat BS. Karbonmonoksit zehirlenmesi. Düzce Üniversitesi Tıp Fak Derg. 2009;11:54-60.

2. Raub JA, Mathiue-Nolf M, Hampson NB, Thom SR. Carbon monoxide poisoning--a public health perspective. Toxicology. 2000;145:1-14.

3. Şen H, Özkan S. Karbonmonoksit zehirlenmesi. TAF Prev Med Bull. 2009;8:351-6.

4. Kırel B, Akın A, Sezgin ME, Şenses EY, Ünal Y. Karbonmonoksit zehirlenmesi ve hiperbarik oksijen tedavisi. Çocuk Sağlığı ve Hast. Derg. 2005;48:164-7.

5. Roderique JD, Josef CS, Feldman MJ, Spiess BD. A modern literature review of carbon monoxide poisoning theories, therapies, and potential targets for therapy advancement. Toxicology. 2015;334:45-58.

6. Gurtovenko AA, Anwar J. Modulating the structure and properties of cell membranes: the molecular mechanism of action of dimethyl sulfoxide. J Phys Chem B. 2007;111:10453-60.

7. Salim AS. Role of oxygen-derived free radical scavengers in the management of recurrent attacks of ulcerative colitis: a new approach. I Lab Clin Med. 1992;119:710-7

8. Broadwell RD, Salcman M, Kaplan RS. Morphologic effect of dimethyl sulfoxide on the blood-brain barrier. Science. 1982;217:164-6

9. Ikeda Y, Long DM. Comparative effects of direct and indirect hydroxyl radical scavengers on traumatic brain oedema. Acta Neurochir Suppl (Wien). 1990;51:74-6.

10. Rosenstein ED. Topical agents in the treatment of rheumatic disorders. Rheum Dis Clin North Am. 1999;25:899-918.
11. Abdullaeva GK, Shakimova BSh. [An evaluation of the efficacy of treating rheumatoid arthritis with preparations for local use]. Revmatologiia (Mosk). 1989;4:35-9

12. Bertelli G, Gozza A, Forno GB, Vidili MG, Silvestro S, Venturini M, et al. Topical dimethyl sulfoxide for the prevention of soft tissue injury after extravasation of vesicant cytotoxic drugs: a prospective clinical study. J Clin Oncol. 1995; 13:2851-5.

13. Kingery WS. A critical review of controlled clinical trials for peripheral neuropathic pain and complex regional pain syndromes. Pain. 1997;73:12339 .

14. Luan ZG, Ma XC, Zhang H, Zhang C, Guo RX. Protective effect of ethyl pyruvate on pancreas injury in rats with severe acute pancreatitis. J Surg Res. 2013; 181:76-84

15. Su X, Wang H, Zhao J, Pan H, Mao L. Beneficial effects of ethyl pyruvate through inhibiting high-mobility group box 1 expression and TLR4/NF$\kappa B$ pathway after traumatic brain injury in the rat. Mediators Inflamm. 2011;2011:807142.

16. Shen H, Hu X, Liu C, Wang S, Zhang W, Gao H, et al. Ethyl pyruvate protects against hypoxic-ischemic brain injury via anti-cell death and antiinflammatory mechanisms. Neurobiol Dis. 2010;37:711-22.

17. Hu X, Cui B, Zhou X, Xu C, Lu Z, Jiang H. Ethyl pyruvate reduces myocardial ischemia and reperfusion injury by inhibiting high mobility group box 1 protein in rats. Mol Biol Rep. 2012;39:227-31.

18. Tsung A, Kaizu T, Nakao A, Shao L, Bucher B, Fink MP, et al. Ethyl pyruvate ameliorates liver ischemia-reperfusion injury by decreasing hepatic necrosis and apoptosis. Transplantation. 2005 Jan 27;79:196-204.

19. Yardan T, Meric M, Bozkurt A, Bilge S, Bas DB, Bedir A, Ozdemir T, Baydin A. The role of heart-type fatty acid-binding protein in the evaluation of carbon monoxide poisoning in rats. Hum Exp Toxicol. 2011;30:124-8.

20. Little JR. Modification of acute focal ischemia by treatment with mannitol and high-dose dexamethasone. J Neurosurg. 1978;49:517-24.

21. Garman RH. Histology of the central nervous system. Toxicol Pathol. 2011;39:22-35.

22. Tokatli F, Uzal C, Doganay L, Kocak Z, Kaya M, Ture M, et al. The potential cardioprotective effects of amifostine in irradiated rats. Int J Radiat Oncol Biol Phys. 2004;58:1228-34.

23. Yıldız O, Can Z, Saral O, Yuluğ E, Oztürk F, Aliyazıcıoğlu R, etal. Hepatoprotective potential of chestnut bee pollen on carbon tetrachloride-induced hepatic damages in rats. Evid Based Complement Alternat Med. 2013;2013:461478.

24. Kao LW, Nañagas KA. Carbon monoxide poisoning. Emerg Med Clin North Am. 2004;22:985-1018.

25. Bojakowski K, Gaciong Z, Grochowiecki T, Szmidt J. Carbon monoxide may reduce ischemia reperfusion injury: a case report of complicated kidney transplantation from a carbon monoxide poisoned donor. Transplant Proc. 2007;39:2928-9.

26. Gorman DF. Carbon monoxide: From toxic poison to brain messenger. S Pac Underwater Med Soc J. 1995;25:77.

27. Gill AL, Bell CN. Hyperbaric oxygen: its uses, mechanism of action and outcomes. QJM. 2004;97:385-95.

28. Güven M. Karbonmonoksit zehirlenmesi: Görünmez kaza. Yoğun Bakım Derg. 2005;5:221-6.

29. Wang W, Li Y, Ren J, Xia F, Li J, Zhang Z. Hydrogen rich saline reduces immunemediated brain injury in rats with acute carbon monoxide poisoning. Neurol Res. 2012;34: 1007-15.

30. Kekec Z, Seydaoglu G, Sever H, Ozturk F. The effect of antioxidants ( $\mathrm{N}$-acetylcysteine and melatonin) on hypoxia due to carbonmonoxide poisoning. Bratisl Lek Listy. 2010;111:189-93.

31. Santos NC, Figueira-Coelho J, e Silva JM, Saldanha C. Multidisciplinary utilization of dimethyl sulfoxide: Pharmacological, cellular, and molecular aspects. Biochem Pharmacol. 2003;65:1035-41. 
32. Rawls WF, Cox L, Rovner ES. Dimethyl sulfoxide (DMSO) as intravesical therapy for interstitial cystitis/bladder pain syndrome: A review. Neurourol Urodyn. 2017;36:1677-84

33. Chang CK, Llanes S, Schumer W. Inhibitory effect of dimethyl sulfoxide on nuclear factor-kappa B activation and intercellular adhesion molecule 1 gene expression in septic rats. J Surg Res. 1999;82:294-9.

34. Essani NA, Fisher MA, Jaeschke H. Inhibition of NF-kappa B activation by dimethyl sulfoxide correlates with suppression of TNF-alpha formation, reduced ICAM-1 gene transcription, and protection against endotoxininduced liver injury. Shock. 1997;7:90-6.
35. Limuro Y, Nishiura T, Hellerbrand C, Behrns KE, Schoonhoven R, Grisham JW, et al. NFkappaB prevents apoptosis and liver dysfunction during liver regeneration. J Clin Invest. 1998;101:802-11.

36. Di Giorgio AM, Hou Y, Zhao X, Zhang B, Lyeth BG, Russell MJ. Dimethyl sulfoxide provides neuroprotection in a traumatic brain injury model. Restor Neurol Neurosci. 2008;26:501-7.

37. Suha T, Asli M, Aynur S, Yunus K, Ahmet M, Selim D, et al. Effects of $\mathrm{N}$-acetylcysteine and ethyl pyruvate on ischemia-reperfusion injury in experimental electrical burn model. Am J Emerg Med. 2016;34:1217-24. 